\title{
Effect of Light Intensity to Chlorophyll and Anthocyanin Content in Mangosteen Leaf
}

\author{
Eko Setiawan \\ Agrotechnology Department, University of Trunojoyo Madura \\ e_setiawan@trunojoyo.ac.id
}

\begin{abstract}
The objective of this study was to understand the light intensity conditions of mangosteen trees to various branch position in canopy. The experiment was conducted using mangosteen trees grown on commercial orchard in Bogor, Indonesia during August - October 2013. Mangosteen trees of three different ages, young (20 years), middle (35 years), and old ages (50 years), each of five trees, are selected for study. Canopy of each tree divided into 9 sectors. The highest light intensity in full sunlight conditions was found in sector 9 were 8.07; 7.53; and 7.74 $\mu \mathrm{mol} M-2 \mathrm{~s}-1$, in young, middle and old age, respectively, in contrast, the lowest light intensity in sector 1 were 0.53; 0.42; and $0.49 \mu \mathrm{mol} M-2 \mathrm{~s}-1$, in young, middle and old age, respectively. Chlorophyll $a / b$ ratio in mangosteen leaves increase gradually as an increase of age, each in young, middle, and old age were 2.20; 2.25; and 2.95, respectively. The highest chlorophyll index was in branch with fruit production, than decrease in dormancy condition, whereas the lowest chlorophyll index in new flush or vegetative condition.
\end{abstract}

Key words: age, chlorophyll, light intensity, mangosteen, sector. 


\section{INTRODUCTION}

Mangosteen

(Garcinia mangostana L.) is a tropical evergreen tree, believed to have originated in the Sunda Islands and the Moluccas (Misra et al., 2009), growing in humid and shaded environmental conditions (Osman and Milan, 2006). Mangosteen, a slow-growing tree, is adapted to shade and regarded as a shade tolerant tree, while shade is essential during the first 2-4 years of growth (Nakasone and Paull, 1998). There are no reports of photoperiod response. The photosynthetic rate is steady over a $27-35^{\circ} \mathrm{C}$ temperature range, under $20-50 \%$ shade (Weibel et al., 1993). Fruit is susceptible to sunburn in direct sunlight (Verheij, 1992).

Mangosteen orchards in Indonesia are generally found in villages and contain several fruit species. Growing mangosteen together with durian, rambutan or longkong is a common practice in Thailand, because growers experienced that the young plants require nurse trees or artificial shade to encourage their growth (Salakpetch, 2005). The objective of this study was to understand the light intensity conditions of mangosteen trees to various sector in canopy.

\section{MATERIALS AND METHODS}

Plant material

The experiment was conducted using mangosteen trees grown on commercial orchard in Bogor, Indonesia during August October 2013. Mangosteen trees of three different ages, young (20 years), middle (35 years), and old ages (50 years), each of five trees, are selected for study. Canopy of

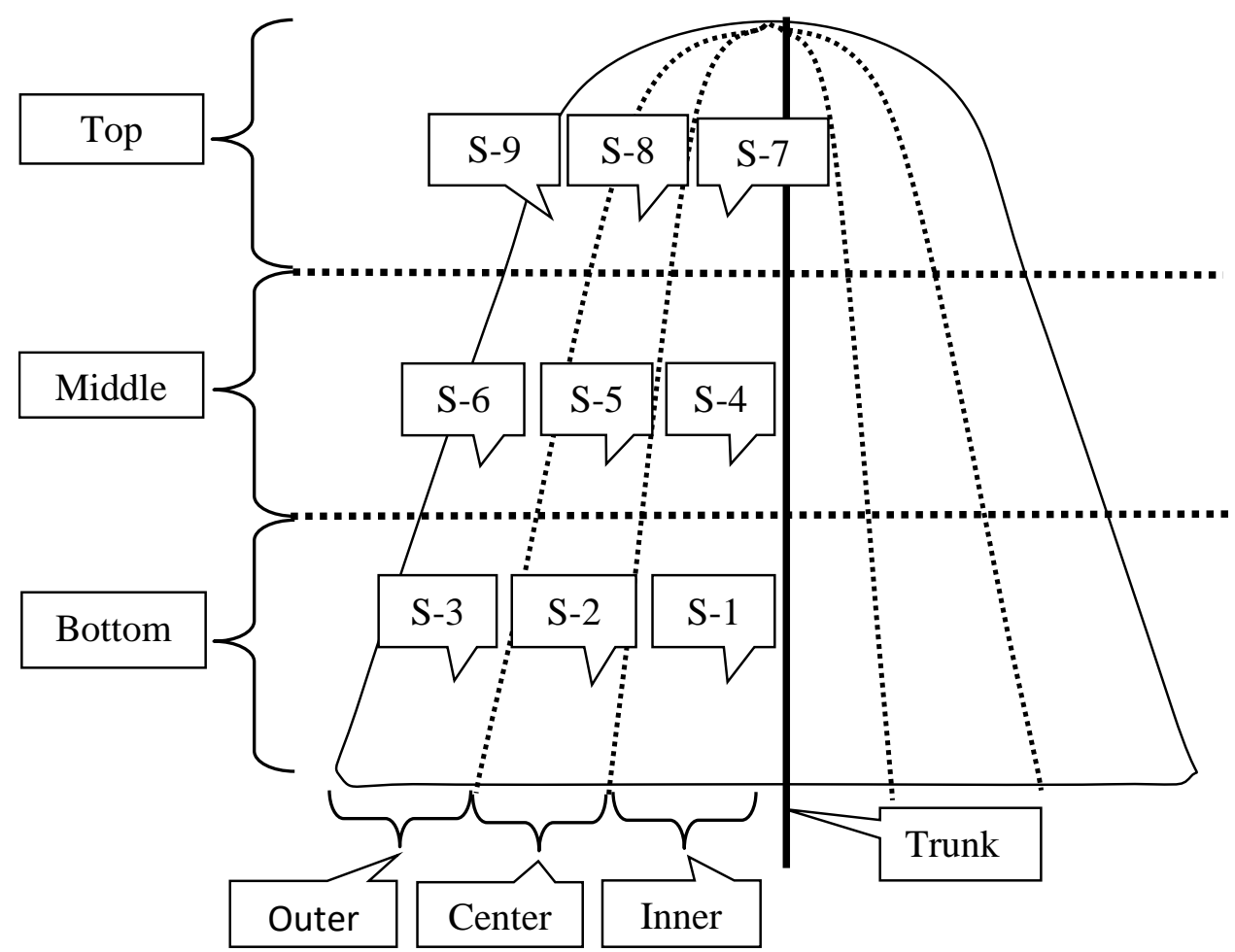

Figure 1. Illustration of the sectors (positions in the canopy, S-1 to S-9) defined for study of mangosteen trees. 
each tree divided into 9 sectors, such as Sector 1 (inner bottom canopy); Sector 2 (center bottom canopy); Sector 3 (outer bottom canopy); Sector 4 (inner middle canopy); Sector 5 (center middle canopy); Sector 6 (outer middle canopy); Sector 7 (inner top canopy); Sector 8 (center top canopy); and Sector 9 (outer top canopy) (Figure 1).

\section{Light intensity and chlorophyll index}

Light Intensity was monitored by Light Meter LI-250A (LI-COR) in each sector per month. The measurement light intensity in each sectors are in full sunlight and cloudy conditions. Using the young, middle, and old age trees, two leaves are collected from 9 sectors in September 2013. The chlorophyll index of leaf samples was measured by a chlorophyll-meter (SPAD-502, Minolta). The chlorophyll contents are determined used the same leaf above. Data were analysed using DSAASTAT.

\section{RESULTS AND DISCUSSION Light intensity}

Plant productivity associated

with the process of plant photosynthesis. The light intensity in full sunlight in orchard conditions are presented in Figure 2. Light intensity at $6.30 ; 7.30 ; 8.30 ; 9.30$ and 10.30 AM were $10.13 ; 54.55 ; 91.14 ; 140.30$ and $174.38 \mu \mathrm{mol} M-2 \quad \mathrm{~s}-1$, respectively and then gradually decrease because cloudy. Daily afternoon conditions in Bogor are cloudy and that followed by rainy.

Figure 3 a shows the light intensity in cloudy conditions. The highest light intensity in cloudy conditions in sector 9 were 0.31 ; 0.32 ; and $0.28 \mu \mathrm{mol} \mathrm{M}-2 \mathrm{~s}-1$ in young, middle and old age, respectively. That followed by sector 8 , sector 6 and sector 3 . Whereas the lowest light intensity in sector 1 were 0.025 ; 0.03; and $0.021 \mu \mathrm{mol} \mathrm{M}-2 \mathrm{~s}-1$ in young, middle and old age, respectively.

Light intensity is not different significant in ages, but different significant in sector. The highest light

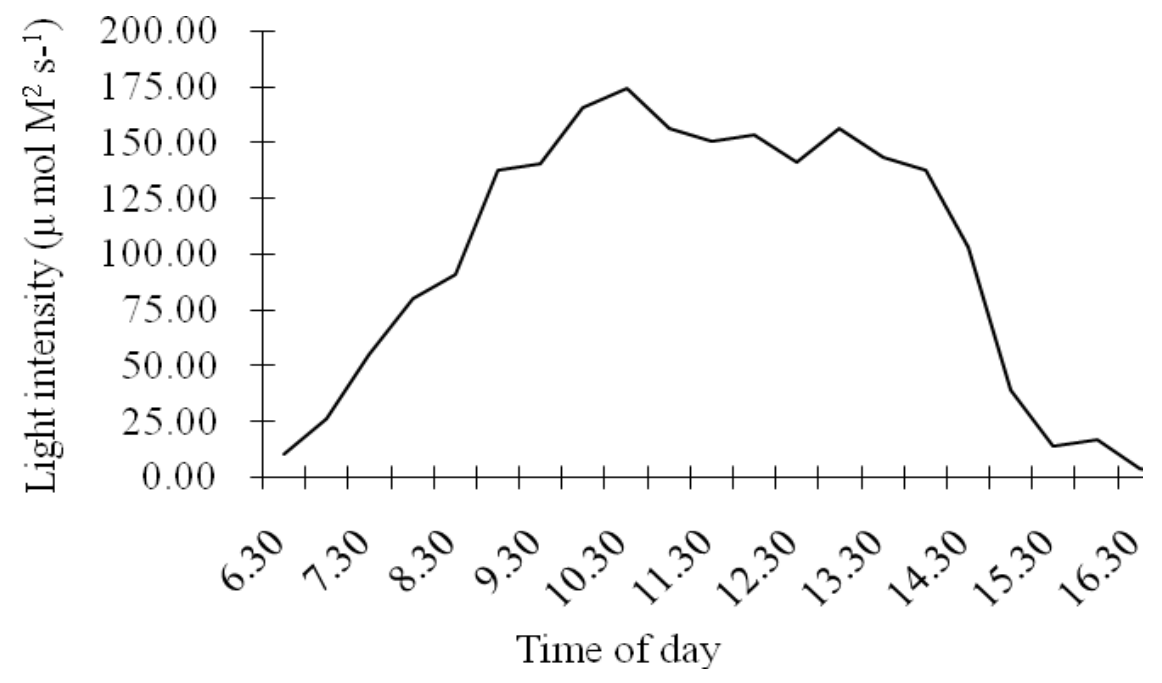

Fig. 2 Curves of diurnal of full sunlight during September 2013 in Bogor. 
intensity in full sunlight conditions was found in sector 9 were 8.07; 7.53; and $7.74 \mu \mathrm{mol} M-2 \mathrm{~s}-1$, in young, middle and old age, respectively (Figure $3 \mathrm{~b}$ ). That followed by sector 8 and sector 6 . In contrast, the lowest light intensity in sector 1 were 0.53 ; 0.42 ; and $0.49 \mu$ mol M-2 s-1, in young, middle and old age, respectively.

\section{Chlorophyll and anthocyanin content}

Chlorophyll contents are not different significant in ages, but different significant inter-sector. Figure 3 showed the highest chlorophyll a content in sector 3; sector 4; sector 5; sector 6; sector 7; sector 8; and sector 9 were 6.19; $5.85 ; 6.72 ; 5.94 ; 6.87 ; 6.87$ and 6.78 $\mu$ mol, respectively. In contrast, the lowest chlorophyll a contents in sector 1 and sector 2 were 5.58 and $5.35 \mu \mathrm{mol}$, respectively. Chlorophyll b content are not different significant, highest in sector 7 and lowest in sector 2 were 3.24 and $2.23 \mu \mathrm{mol}$, respectively.

Both chlorophyll $a$ and $b$ contents decreased gradually as an increase of ages. Average of chlorophyll a content gradually as a decrease of age in young, middle and old age were $6.55 ; 6.44$ and 5.72 , respectively. Average of chlorophyll b content gradually as a decrease of age in young, middle and old age were $3.05 ; 2.95$ and 2.44, respectively. Chlorophyll $a / b$ ratio in mangosteen leaves increase gradually as an increase of age, each in young, middle, and old age were $2.20 ; 2.25$; and 2.95 , respectively. Chlorophyll total lowest in sector 2 and highest in sector 7 were 7.58 and $10.11 \mu \mathrm{mol}$, respectively.

Anthocyanin contents are not different significant both in ages and inter-sector. Figure $3 a$ shows anthocyanin content in young age highest in sector 4 and sector 7, whereas lowest in sector 3 were 6.31; 6.19 and $2.59 \mu \mathrm{mol}$, respectively. Figure $3 \mathrm{~b}$ shows the highest Anthocyanin content in middle age in sector 1 , sector 4 , sector 7 and sector 8 were 7.66 ; 6.76 ; 5.67 ; and $5.44 \mu$ mol, respectively. In contrast, the lowest Anthocyanin content in middle age in sector 6 and sector 9 were 3.48 and $3.91 \mu \mathrm{mol}$, respectively. Figure $3 \mathrm{c}$ shows the highest Anthocyanin content in old age are in sector 1 , sector 4 and sector 5 were $8.59 ; 11.30$ and $10.18 \mu \mathrm{mol}$, respectively. In contrast, the lowest Anthocyanin content in old age in
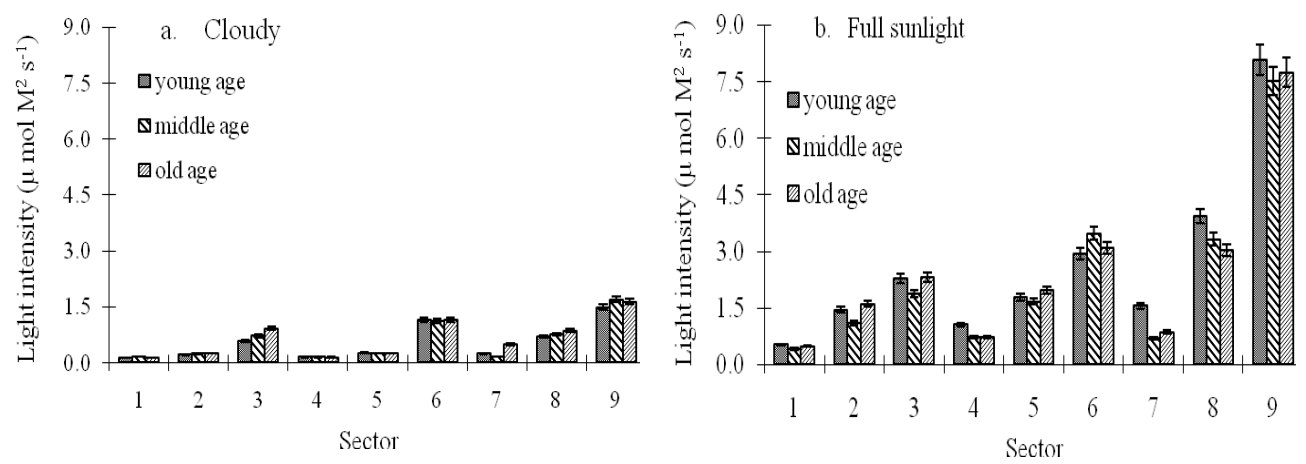

Fig. 3 Comparison of light intensity of mangosteen at various sector in canopy (a) cloudy and (b) full sunlight condition. 

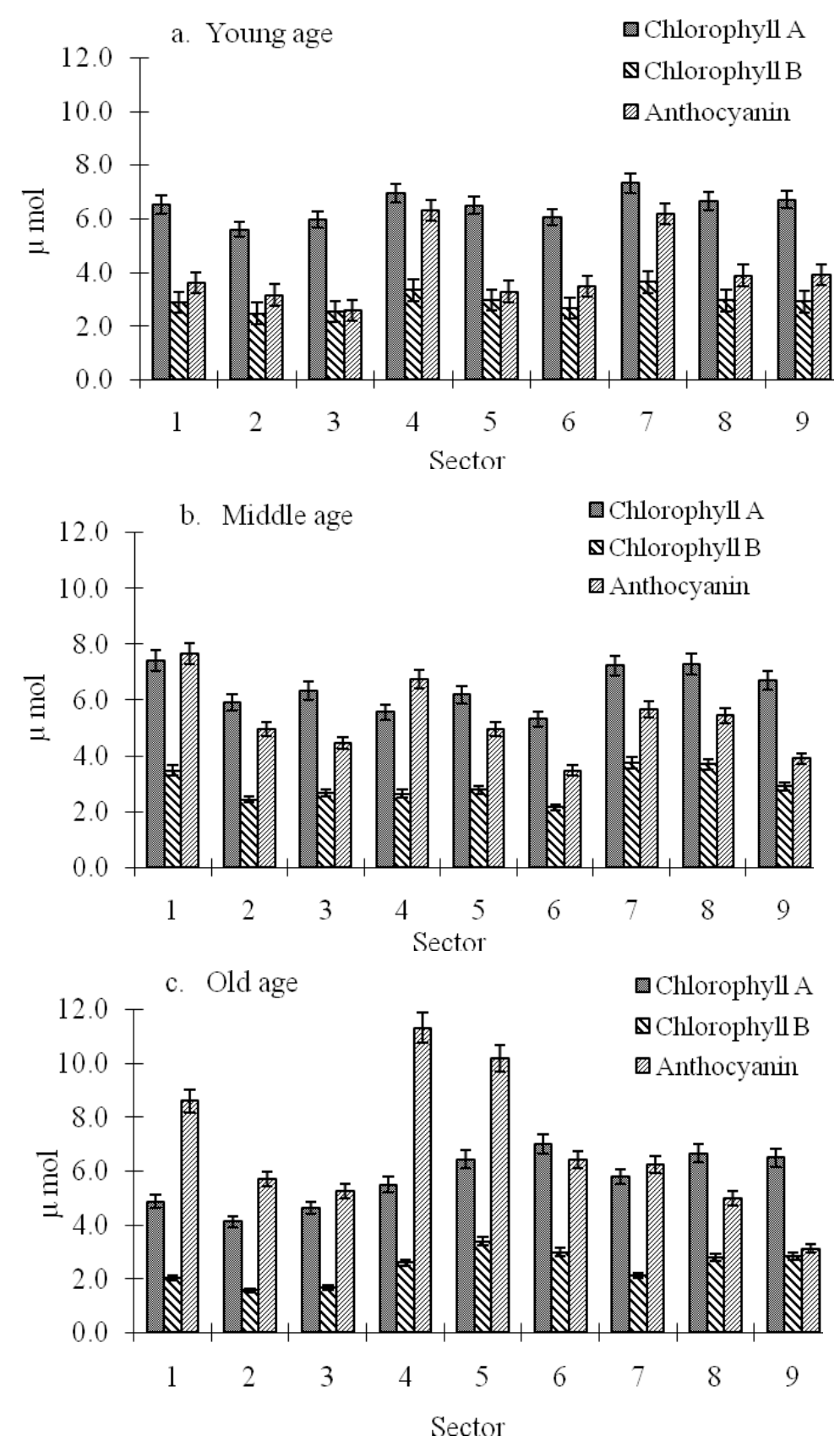

Fig. 4 Comparison of chlorophyll and anthocyanin content in leaves of mangosteen at various sector in canopy (a) young age, (b) middle age and (c) old age.

sector 9 and 8 were 3.11 and $4.98 \mu$ mol, respectively.

Figure 5 shows the relationship between chlorophyll index and chlorophyll content in leaves of mangosteen at various sector in canopy (a) young age, (b) middle age and (c) old age. Table 1 shows comparison of leaves season time of the presence on chlorophyll 
index of leaves. The highest chlorophyll index was in branch with fruit production, than decrease in dormancy condition, whereas the lowest chlorophyll index in new flush or vegetative condition.
The highest light intensity in full sunlight conditions was found in sector 9, in contrast, the lowest light intensity in sector 1 . Sector 9 , sector 6 and sector 3 are outer position in canopy get high light intensity

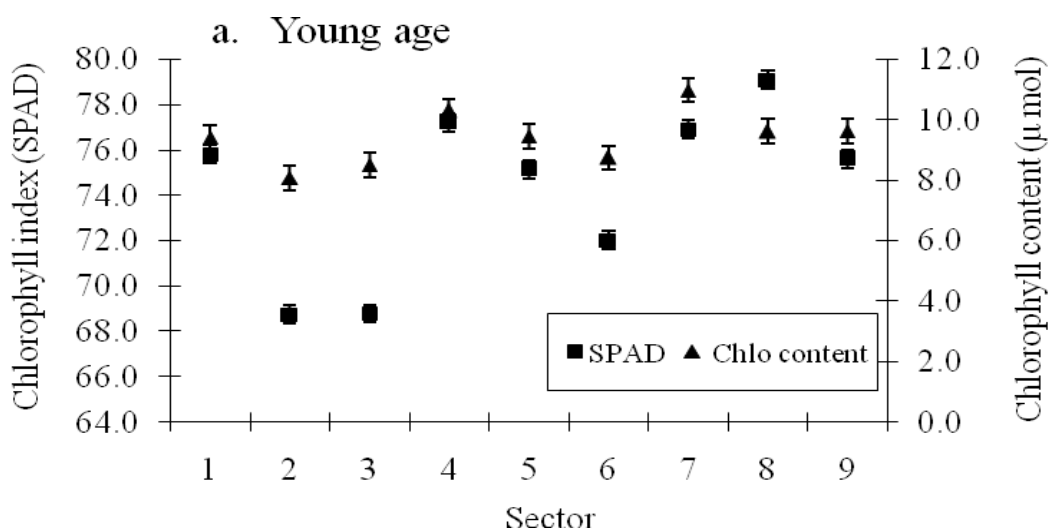

b. Middle age

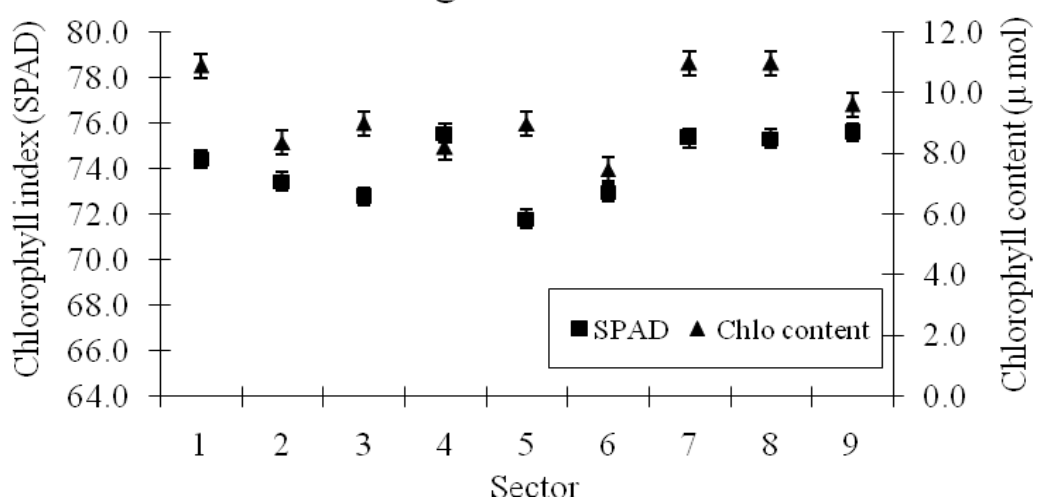

c. Old age

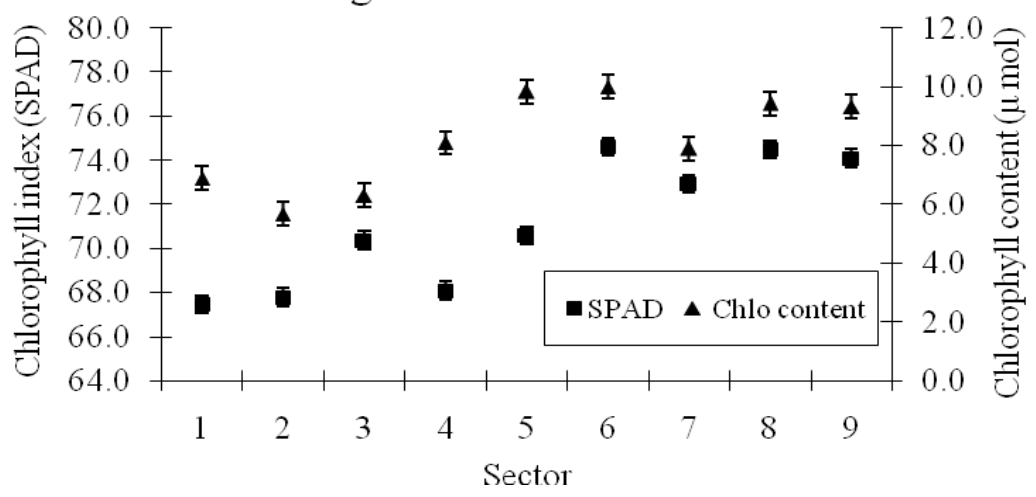

Fig. 5 The relationship between chlorophyll index and chlorophyll content in leaves of mangosteen at various sector in canopy (a) young age, (b) middle age and (c) old age. 
Table 1 Comparison of leaves season time of the presence on chlorophyll index of leaves

\begin{tabular}{clc}
\hline Type of trees & Leaves season time & $\begin{array}{c}\text { Chlorophyll index } \\
\text { (SPAD) }\end{array}$ \\
\hline 1 & With fruit & 71.77231 \\
& Dormancy & 71.58503 \\
2 & New flush / vegetative & 58.99455 \\
& With fruit & 72.63910 \\
3 & Dormancy & 70.93641 \\
& Dormancy & 68.12375 \\
& New flush / vegetative & 55.76864 \\
\hline
\end{tabular}

because unshaded condition. In contrast sector 7 , sector 4 and sector 1 are inner position in canopy get low light intensity because shaded condition. Ramlan (1992), reported increasing light intensity would result in increased value of photosynthesis when light saturation was achieved. Tabatabaei (2008), reported in both shaded and unshaded plants, the index of chlorophyll was increased with increasing $\mathrm{NH} 4$ ratio in the solution. The chlorophyll index (SPAD) in strawberrys were highest in unshaded condition and lowest in shade condition. Issarakraisila (2008), reported both chlorophyll a and $b$ contents in mangosteen per fresh weight were low at full sun and increased gradually as an increase of light shading or lower light intensity. In this study shows both chlorophyll a and $b$ contents decreased gradually as an increase of ages. Issarakraisila (2008), reported chlorophyll $\mathrm{a} / \mathrm{b}$ ratio in mangosteen leaves seedlings was low with an average of 0.808 . In this study shows chlorophyll $\mathrm{a} / \mathrm{b}$ ratio in mangosteen leaves increase gradually as an increase of age, each in young, middle, and old age were $2.20 ; 2.25$; and 2.95, respectively. This mean biggest canopy because increasing ages made dense inner canopy. Dense canopy structure of upper branches has inner and bottom canopy protect from light availability (Setiawan, Poerwanto and Susanto, 2005). Atwell (1999), a lower a/b ratio reflects an increase in light harvesting chlorophyll II complexes relative to reaction centers since both chlorophyll $a$ and $b$ associated with light harvesting complexes, but only chlorophyll a was found in the reaction centers.

\section{SUMMARY}

Chlorophyll a/b ratio in mangosteen leaves increase gradually as an increase of age, each in young, middle, and old age were 2.20; 2.25; and 2.95 , respectively. The highest chlorophyll index was in branch with fruit production, than decrease in dormancy condition, whereas the lowest chlorophyll index in new flush or vegetative condition.

\section{REFERENCES}

Atwell, B., Kriedejmann, P. and Turnbull, C. 1999. Plant in Action: Adaptation in Nature, Performance in Cultivation. Macmillan Publishers, Sydney, Australia.

Issarakraisila, M. and R. Settapakdee 2008. Effects of light intensity on leaf structure and growth of mangosteen seedlings. Acta Hort. 787: 289-292. 
Misra, H., B. K. Dwivedi, D. Mehta, B. K. Mehta, and D. C. Jain 2009. Development and validation of high performance thin-layer chromatographic method for determination of $\alpha$-Mangostin in fruit pericarp of mangosteen plant (Garcinia mangostana L.) using ultraviolet - visible detection. Rec. Nat. Prod. 3 (4):178-186.

Nakasone, H. Y. and R. E. Paull 1998. Mangosteen. In: H. Y. Nakasone and R. E. Paull (eds.). Tropical Fruits, CAB International: 359-369.

Osman, M., and A. R. Milan 2006. Mangosteen-Garcinia mangostana. Southampton Centre for Underutilised Crops, University of Southampton, UK.

Ramlan, M.F., T.M.M. Mahmud, B.M. Hasan and M.Z. Karim. 1992. Studies on Photosynthesis on Young Mangosteen Plants Grown under Several Growth Conditions. Acta Hort. 321: 482-489.

Setiawan, E., R. Poerwanto and S. Susanto. 2005. Produktivitas dan kualitas buah mangis pada berbagai posisi cabang dalam tajuk. J. Habitat 17 (3): 159-174.

Salakpetch, S. 2005. Mangosteen (Garcinia mangostana L.) Juvenility and Pruning in Thailand in Proceedings Fifteenth Annual International Tropical Fruit Conference. Hilo, Hawaii. p: 27-29.

Tabatabaei, S.J., M. Yusefi, and J. Hajiloo. 2008. Effects of shading and $\mathrm{NO} 3 \mathrm{NH} 4$ ratio on the yield, quality and $\mathrm{N}$ metabolism in strawberry. Scientia Hort. 116: 264-272.

Verheij, E. W. M. 1992. Garcinia mangostana. In: E. W. M. Verheij and R. E. Coronel (eds.). Edible fruits and nuts. PROSEA No. 2, Bogor, Indonesia. p: 175-181.

Weibel, J., D. Eamms, E. K. Chacko, W. J. S. Downton and P. Ludders 1993. Gas exchange characteristics of mangosteen (Garcinia mangostana L.) leaves. Tree Physiol. 13: 5569. 